\title{
Functional Group Analysis of Evaporation and Liquid Combustion of Jet-A and Its Surrogate Fuel Based on Quantitative FT-IR Measurements
}

\author{
Yu Cheng Liu ${ }^{1}$ and Brandon Walker ${ }^{2}$ \\ University of Michigan - Flint, Flint, MI, 48502, U.S.A.
}

\begin{abstract}
This paper reports the evaporation and combustion experiments of small amounts of pool liquid fuel and the preliminary quantification of functional groups including: $\mathrm{CH}_{2}$, $\mathrm{CH}_{3}$, t-butyl, iso-propyl and mono-substituted aromatics using light absorbance in the wave number range of $400-4000 \mathrm{~cm}^{-1}$. The goal was to develop a method that formulates evaporation characteristics for a complex real fuel and use the results to establish a surrogate's evaporation rate associated with real fuel's functional group evaporation rates. Jet-A (POSF-4658) was selected as the real fuel target in this study and a simple mixture of n-decane/iso-octane/toluene was selected to be the surrogate. The experiments included boiling and a pool fire test of $10 \mathrm{~mL}$ liquid fuel samples in a Petri dish. The fuel sample liquid mass was recorded before and after each experiment and the liquid fuel samples were collected using a needle at the end of each experiment. The attenueated total reflection (ATR) module of a Fourier Transform infrared (FT-IR) spectrometer was used to facilitate a large number of liquid measurements. The correlation between concentration and transmittance of each functional group was provided by simple mixtures with known compositions. Results show that the evaporation characteristics of Jet-A and the surrogate mixture are extremely different in terms of time evolution of functional group concentrations and total time. Therefore it suggests the evaporation feature of the surrogate mixture itself is less useful to modeling the evaporation of Jet-A. Moreover, the analyses show that the functional group evolutions during evaporation and pool fire experiments of Jet-A were very similar suggesting the functional group consumptions from liquid combustion may be represented by evaporation.
\end{abstract}

$\begin{array}{ll}\text { Nomenclature } \\ \mathrm{C} & =\text { concentration in the liquid sample } \\ 1 & =\text { optical path length for Beer-Lambert Law } \\ \mathrm{I} & =\text { transmittance with samples } \\ \mathrm{I}_{0} & =\text { transmittance without samples } \\ \sigma & =\text { cross section for Beer-Lambert Law }\end{array}$

\section{Introduction}

I IQUID hydrocarbon fuels have been used for aerospace propulsion since the late 1800s and the demand will continue to increase for decades to come $\mathrm{e}^{1,2}$. A large portion of these fuels are derived from the distillation process of crude oil and other liquid fuels with demonstrated potential are from synthesis of bio-feedstock ${ }^{3-6}$. The composition of these fuels are usually very complex and thus it has been difficult to develop a model that details the behaviors that are critical to its use and further design. A surrogate fuel is a simple mixture designed to emulate

\footnotetext{
${ }^{1}$ Assistant Professor, Department of Computer Science Engineering and Physics, Murchie Science Building 207, 303 E. Kearsley St., Flint, MI 48502, AIAA Member.

${ }^{2}$ Undergraduate Stundent, Department of Computer Science Engineering and Physics, Murchie Science Building 207, 303 E. Kearsley St., Flint, MI 48502.
} 
some behaviors, if not all, of complex fuels so that behavioral prediction of the real complex fuel can be realized through surrogate simulation without having to deal with the much more complex composition of the real fuel.

Some surrogate fuels are proposed to match jet fuel's gas phase combustion ${ }^{7-11}$. The selection of surrogate fuel components and their compositions have been directed to match the carbon numbers and general functional groups ${ }^{9}$. More specific and thorough considerations may include the process of matching the derived cetane number (DCN), hydrogen to carbon ratio $(\mathrm{H} / \mathrm{C})$, molecular weight $(\mathrm{MW})$, and threshold sooting index $(\mathrm{TSI})^{12,13}$. A series of surrogates has been developed based on the properties of Jet-A (POSF-4658) and tested in several gas phase combustion utilities (shock tube, counter flow flame, variable pressure flow reactor, and rapid compression machine ...etc) to demonstrate the methodology ${ }^{12,13}$. The results from those gas phase combustion experiments show fairly good agreement between Jet-A and the surrogates. More recent advances include the nuclear magnetic resonance (NMR) results ${ }^{14}$ that indicate more details of fuel functional groups in the process of formulating surrogate composition.

As the fuel is usually injected in the practical combustion systems as a liquid phase, the local liquid-vapor equilibrium at the liquid surface and the rate of different species being released from the liquid should play a very substantial role in a multi-phase combustion process. Due to the fact that each component in a mixture has its distinct volatility and equilibrium parameter with various other components, developing an evaporation surrogate for a real complex fuel like Jet-A may be as equally challenging as developing a combustion surrogate. A more mature area that is relevant to the problem here is the distillation of real complex fuels ${ }^{10,15,16}$. While the classification and quantification of fuel distillates at different distillation volume fraction provides very valuable information for the evaporation of complex fuels, there has not been a consensus regarding the specific properties for a surrogate to match with the target fuel for evaporation purposes. Moreover, the question that motivated this study was whether the information obtained from distillation can be carried over to the evaporation during liquid combustion. Namely, as the preferential evaporation of fuel components in a mixture is a well-observed phenomenon, the present study attempts to discover the preferential consumption of particular species or functional groups during liquid combustion that may alter the results of preferential evaporation from fuel distillation experiments. Figure 1

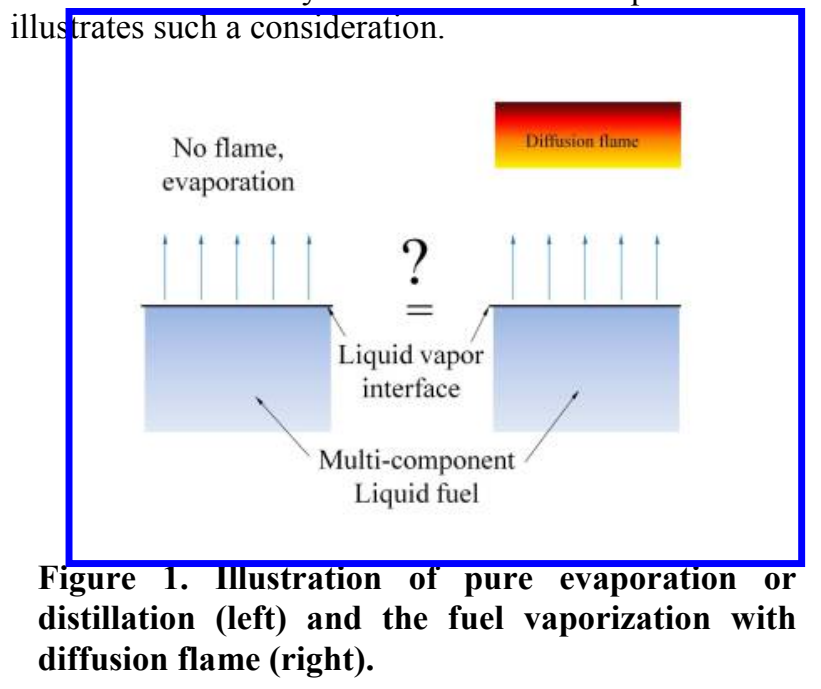

Among the considerations of developing a gas phase combustion surrogate, the amount of similar functional groups (or radicals ${ }^{13}$ ) provided by the prevaporized surrogate is the critical factor in order to mimic the combustion kinetics in gas phase. Similarly, it is important to control the evaporation rate of each surrogate component such that similar amounts of similar functional groups are released into gas phase to creating a similar radical pool in gas phase. The concentration of important functional groups from either liquid or gas samples during evaporation or liquid combustion becomes a piece of necessary information. The quantification of these functional groups may be realized by analyzing infrared spectra of the fuel sample obtained using Fourier-transform infrared (FT-IR) spectroscopy. Note that gas chromategraph with mass spectroscopy (GC-MS) may be able to give very detailed identification for the fuel components, but for surrogate development purposes functional group lumping is more important, which may not require detailed GC-MS information.

FT-IR spectra have been used in several combustion experiments to reveal the concentration of combustion gases like $\mathrm{CH}_{4}, \mathrm{C}_{2} \mathrm{H}_{4}, \mathrm{CH}_{2} \mathrm{O}, \mathrm{H}_{2} \mathrm{O}$...etc. at high temperature and pressures ${ }^{17,18}$. Techniques of laser absorption have been used to detect hydrocarbon fuel concentration using the strong absorption of gaeous hydrocarbons at $3.39 \mu \mathrm{m}$ $\left(\sim 2950 \mathrm{~cm}^{-1}\right)^{19}$ and more recently it was found possible to detect iso-butene using the absorption of a much longer wavelength $11.3 \mu \mathrm{m}\left(885 \mathrm{~cm}^{-1}\right)^{20}$ generated by a wavelength tunable quantum cascade laser. Typical FT-IR measurements provide the light absorbance over a wider range of wavelength $(\mu \mathrm{m})$ or wave number $\left(\mathrm{cm}^{-1}\right)$. In particular, the attenuated total reflection (ATR) module of a FT-IR can be used as a very convient platform for room temperature liquid samples as it does not require a large amount of liquid for measurement and is easy to clean and change from sample to sample. Figure 2 shows the FT-IR ATR results for Jet-A (black) and its surrogate (mixture of decane, iso-octane, and toluene) (red). The peak intensities are presented as absorbance with 1.0 being total 
absorption and 0.0 as total transmission. As shown in Fig. 2, there are clearly identifiable peaks in the range of $2800-3000 \mathrm{~cm}^{-1}, 1300-1500 \mathrm{~cm}^{-1}$, and $600-900 \mathrm{~cm}^{-1}$ for both Jet-A and the surrogate. The corresponding vibration and stretch mode of these peaks will be discussed in the next section. The spectra show in Fig. 2 provide an opportunity for quantifying various functional groups (each as a lumped group) in a fuel mixture regardless of the variety of combination of those groups. The evolution of these peaks can be used to reveal the preferential evaporation in terms of the amount of functional groups.

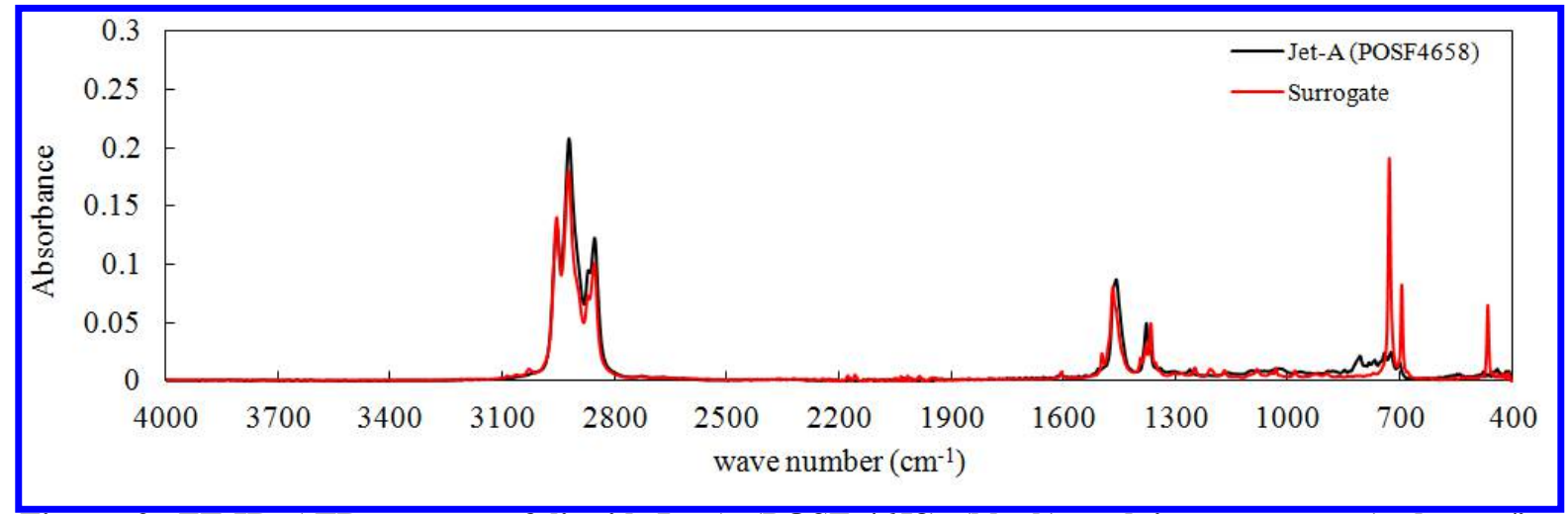

Figure 2. FT-IR ATR spectra of liquid Jet-A (POSF-4658) (black) and its surrogate (n-decane/isooctane/toluene $0.427 / 0.33 / 0.243$ mole fraction) (red).

In this study, we report the evaporation of a $10 \mathrm{~mL}$ quantity of liquid Jet-A and the surrogate at its boiling condition and the pool fire of the same amount of liquid Jet-A. Noted that the pool fire of the surrogate may not be relevant because the main focus here is to match the experimental results of Jet-A.

\section{Experimental Methods}

\section{A. Evaporation experiments}

Compraring with typical distillation experiments that deal with more than $500 \mathrm{~mL}$ of liquid and require a longer experiment time, the evaporation experiments reported here use very small amounts of liquid fuels $(10 \mathrm{~mL})$. Sampling from the same batch of liquid during boiling may introduce artifacts to the distillate weight percentage so a set of experiments with different end times was performed and the sample was always collected at the end of each experiment.

The simple procedures were developed as follows: 1) weigh an empty Petri dish; 2) measure $10 \mathrm{~mL}$ liquid fuel using a graduate cylinder; 3) pour the fuel into the Petri dish and weigh it; 4) put the dish containing $10 \mathrm{~mL}$ liquid fuel onto a hot plate (around $260^{\circ} \mathrm{C}$, it took less than 2 seconds for the liquid fuel to reach a boiling state); 5) after a designed time $t$, terminate the experiment by removing the dish from the hot plate to the precision scale and measure the weight; 6) use a needle to quickly extract the liquid sample (around $2 \mathrm{~mL}$ ) and seal the needle for later FT-IR analysis. Steps 5) and 6) were performed within 10 seconds to minimize uncertainties due to continuing evaporation of fuel on the scale. Figure 3 ( $a, b, c, d, e)$ illustrates the above procedures for evaporation experiments. All the above procedures were realized in a ventilation hood.

For the surrogate fuel (n-decane/iso-octane/toluene with a molar ratio of $0.427 / 0.33 / 0.243^{12}$, or a volumetric ratio of $0.51 / 0.33 / 0.16^{21}$ ) and the Jet-A (POSF-4658) tested in this study, the total evaporation time was less than 3 minutes. Therefore the evaporation time $t$ for separate experiments was designed to be $0 \mathrm{~s}, 20 \mathrm{~s}, 40 \mathrm{~s}, 60 \mathrm{~s}$, .... at a $20 \mathrm{~s}$ increment until the fuel was completely vaporized near $180 \mathrm{~s}$. The chemicals for surrogate components were obtained from Sigma-Aldrich with purity higher than 99\%. The Jet-A (POSF-4658) was obtained from the Wright Patterson Air Force Base of USA.

Because there exists small differences between the initial fuel mass from run to run, the results will be shown in a base of vaporized mass percentage. The readability of the scale (Sartorius Corporation, SECURA613-1S) was $0.001 \mathrm{~g}$. The weight loss during the 10 second of weighing and sample extraction at the end of experiment was usually less than $0.05 \mathrm{~g}$, which is about $0.6 \%$ of a $10 \mathrm{~mL}$ (around $8 \mathrm{~g}$ ) fuel.

\section{B. Combustion Experiments}

The combustion experiments reported in this study were simple pool fire experiments that consumed the $10 \mathrm{~mL}$ liquid Jet-A fuel in the Petri dish. The experimental procedures were as follows: 1) same as 1) to 3) in evaporation 
experiments; 2) preheat the fuel using the hot plate (it took less than 2 seconds to reach a boiling state); 3) place the dish on a room temperature plate and ignite the hot liquid using a propane flame (note that Jet-A liquid is difficult to ignite using a propane flame at room temperature); 4) same as 5) to 6) in evaporation experiments for sample collection. The pool fire flame consumed the liquid fuel (Jet-A) within 3 minutes and the incremental time interval between different runs was 20 seconds. Figure 3 ( $a, b, f, g, d, e)$ illustrates the procedures for a pool fire experiment. All the above procedures were completed in a ventilation hood.

In combustion experiments, the flame provided the heat to quickly vaporize the liquid fuel therefore the dish did not need to stay on the hot plate during the combustion process. When the hot fuel was being weighed at the end of experiment, the weight variation within the 10 second window of weighing and sample extraction was similar to the evaporation case since the fuel was also near its boiling point.

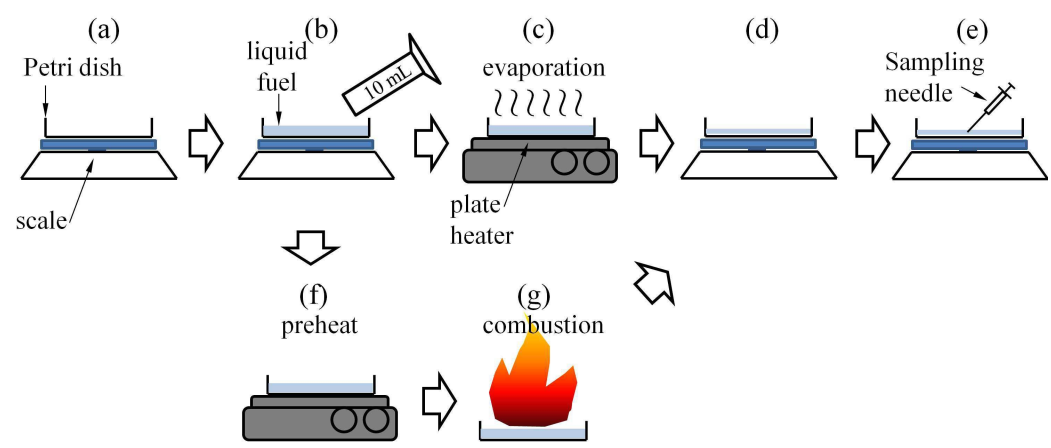

Figure 3. Illustration of the experimental procedures (a) weigh the empty Petri dish, (b) add $10 \mathrm{~mL}$ of liquid fuel and weigh it, (c) place the dish on a hot plate for evaporation experiments, (d) weigh the fuel and Petri dish after time t, (e) collect the liquid fuel sample using a needle, (f) preheat the fuel, (g) ignite the preheated fuel for combustion experiments. Steps for an evaporation experiment are a, b, c, d, e, and for an combustion experiment are $a, b, f, g, d, e$.

\section{FT-IR Anlayses}

The samples extracted from the evaporation and combustion experiments were tested using the ATR module of a FT-IR spectrometer (Thermo Scientific Nicolet iS50). The ATR measurement does not require salt windows or a cell to perform the analysis and only requires very little amount of liquid sample on the analysis surface. The measurements for liquid samples were performed at room temperature and atmospheric pressure to avoid peak broadening effects ${ }^{22}$. The volume of samples (around $2 \mathrm{~mL}$ ) collected from the experiment were much more than what is required by an ATR analysis. After the background peaks were collected, a few droplets were placed on the ATR window surface. The scanning range was from $400 \mathrm{~cm}^{-1}$ to $4000 \mathrm{~cm}^{-1}$ with a reolustion of $0.4 \mathrm{~cm}^{-1}$. All the absorbance spectra shown in this study are the averaged data from 5 individual scans of the same sample.

The raw data from FT-IR is the absorbance in a function of wave number $\left(\mathrm{cm}^{-1}\right)$. Table 1 lists the wave numbers of prominent peaks that are relevant to the functional groups of interests in this study.

Table 1. A list of absorbance wave numbers $\left(\mathrm{cm}^{-1}\right)$ and their corresponding light absorption modes ( $v$ : stretch vibration, $\delta$ : bending vibration, subscript s: symmetrical, as: asymmetrical. $)^{23}$

\begin{tabular}{|c|c|}
\hline Light absorption mode & Wave number $\left(\mathrm{cm}^{-1}\right)$ \\
\hline $\begin{array}{c}v_{\text {as }} \mathrm{CH}_{3} \text { (two } \mathrm{C}-\mathrm{H} \text { extending, one } \\
\text { contracting) }\end{array}$ & $\sim 2954$ \\
\hline$v_{\mathrm{as}} \mathrm{CH}_{2}$ & $\sim 2921$ \\
\hline $\begin{array}{c}v_{\mathrm{s}} \mathrm{CH}_{3} \text { (all three } \mathrm{C}-\mathrm{H} \text { extending and } \\
\text { contracting in phase) }\end{array}$ & $\sim 2870$ \\
\hline$v_{\mathrm{s}} \mathrm{CH}_{2}$ & $\sim 2853$ \\
\hline$\delta_{\mathrm{s}} \mathrm{CH}_{2}$ & $\sim 1465$ \\
\hline$\delta \mathrm{C}-\mathrm{H}$ for t-butyl group & $\sim 1393$ \\
\hline$\delta \mathrm{C}-\mathrm{H}$ for iso-propyl group & $\sim 1365$ \\
\hline Aromatic C-H out of plane bending & $600-900$ \\
\hline
\end{tabular}


In order to convert the absorbance to an absolute concentration, FT-IR measurements were also performed for a various combination of surrogate components, i.e. decane (D), iso-octane (S), and toluene (T), D1S1, D1S2, D2S1, S1T1, S1T2, S2T1, D1T1, D1T2, D2T1, D1S1T1 (the numbers stand for volumetric ratios) and the three component surrogate mixture described in evpoartion experiment. Based on the Beer-Lambert Law of light absorption:

$$
\mathrm{I} / \mathrm{I}_{\mathrm{o}}=\exp (-\sigma \times l \times \mathrm{C})
$$

According to Eq. (1), $\ln (\mathrm{I})$ should be proportional to concentration C. The absolute concentration of each functional group is the product of component concentration $(\mathrm{mole} / \mathrm{mL})$ and the number of functional groups listed in Table 2. Figure 4 shows the graph of $\ln (\mathrm{I})$ vs. functional group concentration C. Most data collected formed clear straight lines except for the more scattered data from $\mathrm{CH}_{3}, 2954 \mathrm{~cm}^{-1}$ and $\mathrm{CH}_{3}, 2872 \mathrm{~cm}^{-1}$. This is speculated to be the probability of various stretching motions (cf. Table 1) that may slightly vary with the adjacent molecular structure. One other possibility is that the absolute peak intensity may be a result of a sum of neighbor overlapping peaks, especially for the region of $2800-3000 \mathrm{~cm}^{-1}$.

Table 2. A list of absorbance wave numbers $\left(\mathrm{cm}^{-1}\right)$ and their corresponding light absorption modes.

\begin{tabular}{|c|c|c|c|c|c|}
\hline & $\mathrm{CH}_{2}$ & $\mathrm{CH}_{3}$ & t-butyl C & iso-propyl C & $\begin{array}{c}\text { Aromatic } \\
\mathrm{CH}\end{array}$ \\
\hline Decane & 8 & 2 & 0 & 0 & 0 \\
\hline Iso-octane & 1 & 5 & 1 & 1 & 0 \\
\hline Toluene & 0 & 1 & 0 & 0 & 5 \\
\hline
\end{tabular}
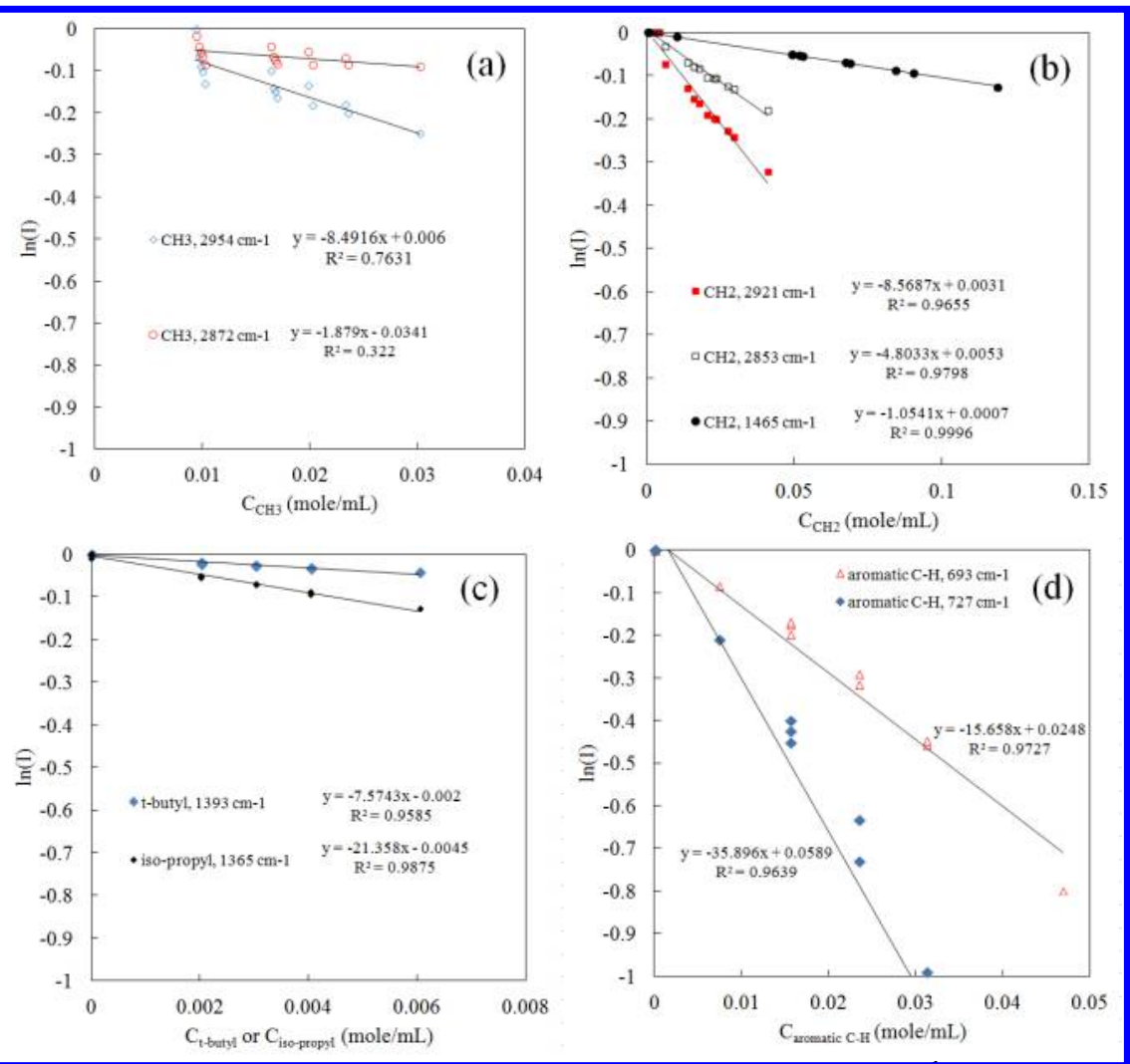

Figure 4. $\ln$ (I) vs. functional group concentration (a) $\mathrm{CH}_{3}$ at 2954 and $2872 \mathrm{~cm}^{-1}$, (b) $\mathrm{CH}_{2}$ at 2921 , 2853, and $1465 \mathrm{~cm}^{-1}$, (c) t-butyl at $1393 \mathrm{~cm}^{-1}$ and iso-propyl at $1365 \mathrm{~cm}^{-1}$, (d) aromatic C-H at 727 and $693 \mathrm{~cm}^{-1}$. The absorbance data come from various volumetric combination of n-decane, iso-octane, and toluene. 


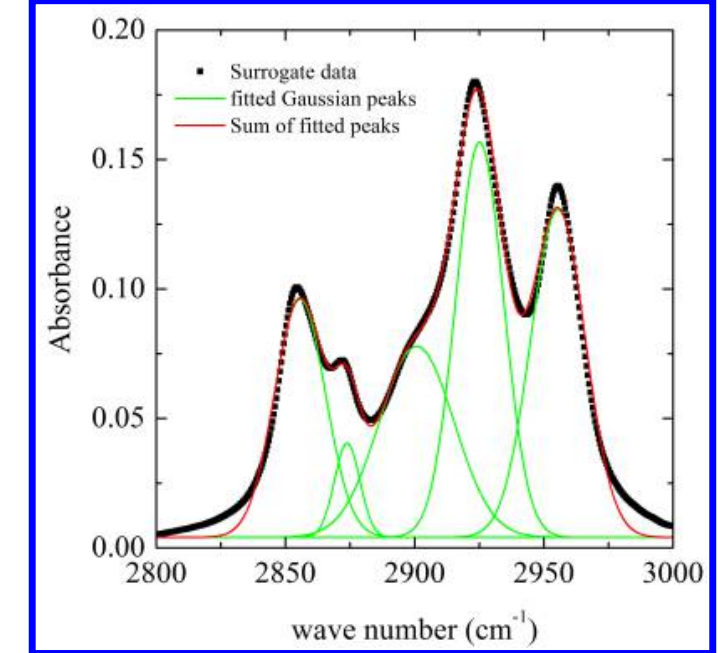

Figure 5. FT-IR ATR spectra of the surrogate mixture (black data) in the range of 2800-3000 $\mathrm{cm}^{-1}$ and the Gaussian peak fittings (green curves) and the sum of fitted peaks (red curves).
Figure 5 shows five Gaussian peaks fitted to the spectra of the surrogate mixture in the range of 2800$3000 \mathrm{~cm}^{-1}$ using the multi-peak fittings tool of Origin Pro 8. The graph suggests that the observed peak intensity (black data) near $2853 \mathrm{~cm}^{-1}$ is very close to the local fitted green curve. This means directly using the FT-IR data without fittings would give nice correlations since the peak at this location is more isolated and not affected by other peaks. On the contrary, the fitted peak around $2872 \mathrm{~cm}^{-1}$ is almost one half of the observed intensity. As a result, the observed intensity at near 2872 $\mathrm{cm}^{-1}$ may have contribution from the broadening of neighbor peaks leading to a set of more scattering data (with a very low $\mathrm{R}^{2}$ value, 0.322 ). The calibration for $\mathrm{CH}_{3}$ concentration would have to come from the data from $2954 \mathrm{~cm}^{-1}$. Among all $\mathrm{CH}_{2}$ data (Fig. 5b), the one from $1465 \mathrm{~cm}^{-1}$ provides the best $\mathrm{R}^{2}$ value and the 1465 $\mathrm{cm}^{-1}$ is also more isolated than the ones near $2900 \mathrm{~cm}^{-1}$. Therefore the calibration for $\mathrm{CH}_{2}$ in the later discussion is provided by the linear fit of $1465 \mathrm{~cm}^{-1}$ in Fig. $4 \mathrm{~b}$. Note that the correlations of t-butyl and iso-propyl (Fig. 4c)

come exclusively from the concentration of iso-octane. Inclusion of other chemicals may be considered for the calibration purposes in the future. The correlations provided in Fig. 4 should be able to handle a mixture of ndecane, iso-octane, and toluene. However, in the hope of covering most functional groups identified from the Jet-A spectrum using surrogate fuel components, there are still some aromatic functional groups that can not be solely covered by toluene. For instance, aromatics with various benzene substitutions cause the inconsistency found in Fig. 2 in the range of $600-900 \mathrm{~cm}^{-1}$. This issue will be briefly discussed in the next section.

\section{Results and Discussions}

The evaporation experiments were carried out for both Jet-A and the 3 component surrogate (cf. Fig. 2). Figure 6 shows the time evolution of vaporized mass percentage for the evaporation of Jet-A and its surrogate, as well as JetA combustion. The results suggest that the evaporation rate of surrogate was much faster than that of Jet-A. The combustion of Jet-A consumes the fuel at a very similar rate compared to evaporation.

Figure 7 shows the absorbance peaks from evaporation experiments of the surrogate with selected time at the three wave number ranges of interests: (a) $2800-3000 \mathrm{~cm}^{-1}$, (b) $1300-1550 \mathrm{~cm}^{-1}$, (c) $600-800 \mathrm{~cm}^{-}$ 1 . As evaporation time increases, there are significant and consistent increases in the peak intensities of 2853 $\mathrm{cm}^{-1}$ and $2921 \mathrm{~cm}^{-1}$ (both representing $\mathrm{CH}_{2}$ ). A slight decrease of $\mathrm{CH}_{3}$ concentration can be found at 2954 $\mathrm{cm}^{-1}$. The peak at $1365 \mathrm{~cm}^{-1}$ (iso-propyl group) (Fig. $7 \mathrm{~b})$ decreases with time. This trend exclusively indicates that the amount of iso-octane in the liquid mixture decreases during evaporation. The weakening peak at $693 \mathrm{~cm}^{-1}$ in Fig. 7c suggests the toluene concentration decreases over time. It may not be necessary to discuss all the peaks that exhibit changes in Fig. 7 because only one peak is needed for a particular functional group to convert peak intensities to concentration.

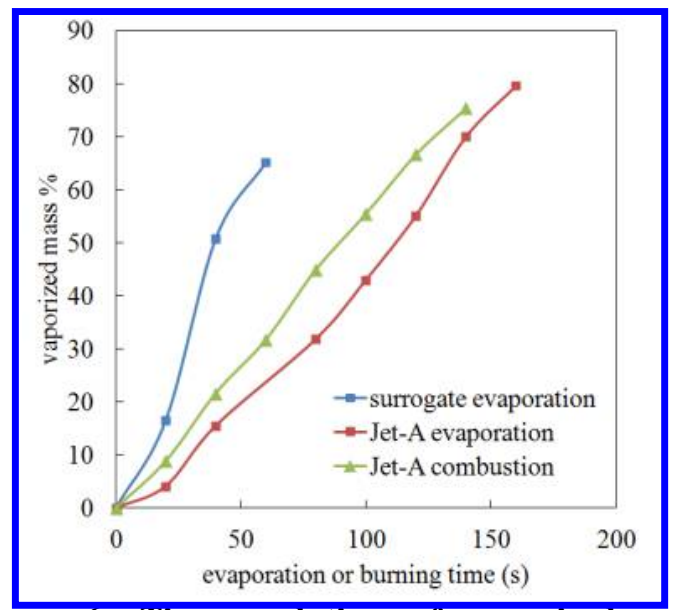

Figure 6. Time evolution of vaporized mass percentage for evaporation of Jet-A and its surrogate and the combustion of Jet-A. 


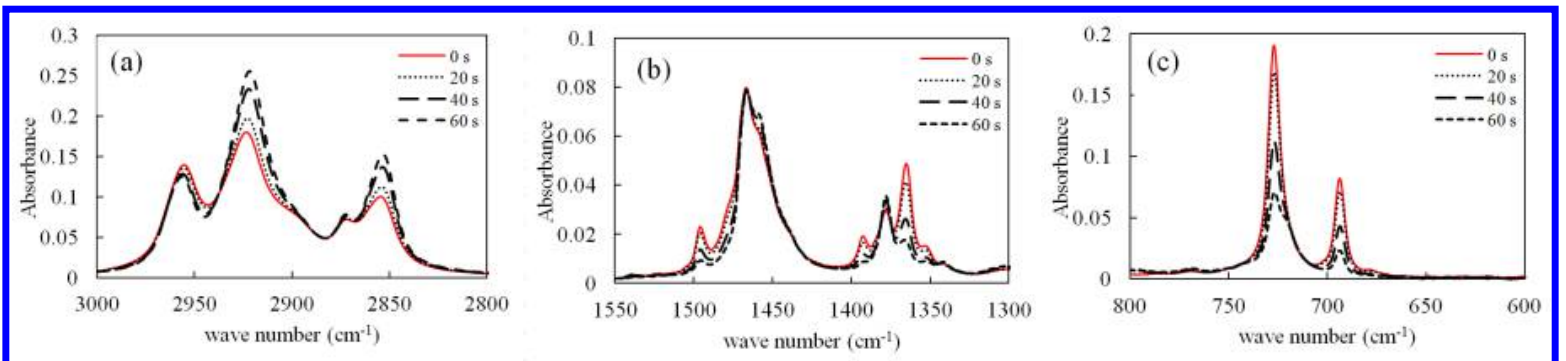

Figure 7. Evolution of absorbance peaks from the evaporation experiments of the surrogate fuel: (a) 2800$3000 \mathrm{~cm}^{-1}$, (b) $1300-1550 \mathrm{~cm}^{-1}$, (c) $600-800 \mathrm{~cm}^{-1}$.

Figure 8 shows the results from evaporation experiments of Jet-A in a similar fashion as in Fig. 7. It is quite obvious that peak intensities in Fig. 8 stay relatively constant compared to the surrogate fuel peaks shown in Fig. 7. As there are only three components in the surrogate mixture, the evaporation is only governed by the phase equilibtrium between n-decane, iso-octane, and toluene. As n-deacne is elected to be the least volatile component in the surrogate, the evaporation is strongly in favor of iso-octane and toluene turning into significant decrease in peak intensities of iso-propyl $\left(1365 \mathrm{~cm}^{-1}\right)$ and aromatic C-H $\left(693 \mathrm{~cm}^{-1}\right)$ shown in Figs. $7 \mathrm{~b}$ and $7 \mathrm{c}$. The evaporation time of the surrogate was around $60 \mathrm{~s}$ where on the contrary, Jet-A consists of chemical compounds with a boarder range of carbon numbers and therefore volatility.
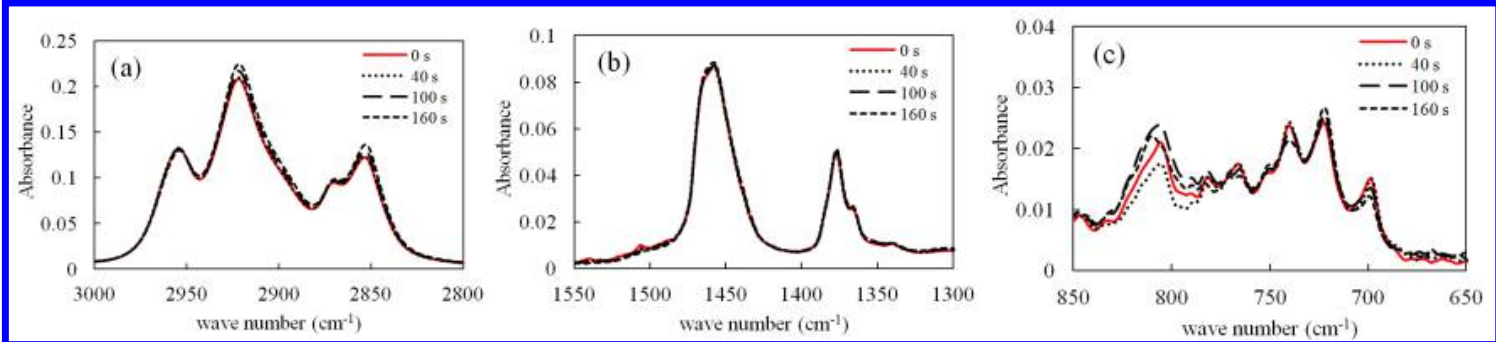

Figure 8. Evolution of absorbance peaks from the evaporation experiments of Jet-A (POSF-4658): (a) $2800-3000 \mathrm{~cm}^{-1}$, (b) $1300-1550 \mathrm{~cm}^{-1}$, (c) $600-800 \mathrm{~cm}^{-1}$.

Figure 9 shows the evolution of absorbance peaks from Jet-A combustion experiments. Interestingly, the functional groups consumption shown in the range of 1300-3000 $\mathrm{cm}^{-1}$ by combustion (Fig. 9a and $9 \mathrm{~b}$ ) tends to be very similar to the consumption by evaporation (Fig. $9 \mathrm{a}$ and $9 \mathrm{~b}$ ). The differences found for aromatics groups (Fig. 8c and $9 \mathrm{c}$ ) are in the scale of 0.01 of absorbance, which is still very small.
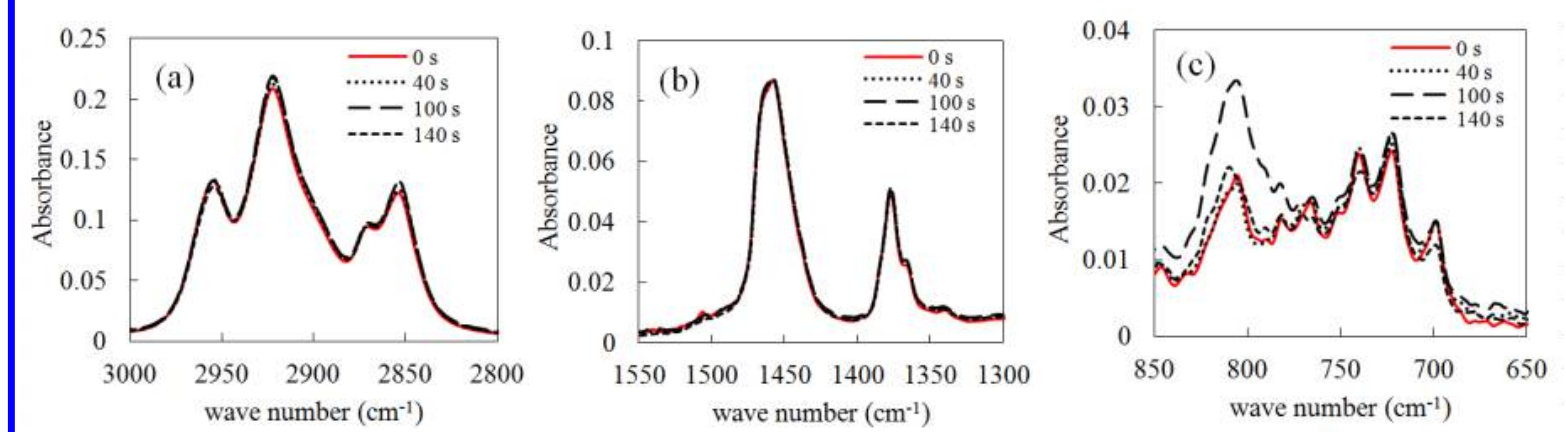

Figure 9. Evolution of absorbance peaks from the combustion experiments of Jet-A (POSF-4658): (a) $2800-3000 \mathrm{~cm}^{-1}$, (b) $1300-1550 \mathrm{~cm}^{-1}$, (c) $600-800 \mathrm{~cm}^{-1}$.

Figure 10 shows the evolution of functional group concentrations using the absorbance in Figs. 7 to 9 and the correlation developed between peak instensity and concentration (Fig. 4). It is evident that the evpoartion characteristics of the surrogate are very different from that of Jet-A. This would suggest that if we must use this suite of surrogate to match the gas phase combustion, the functional group evaporation rate must be fine tuned to match 

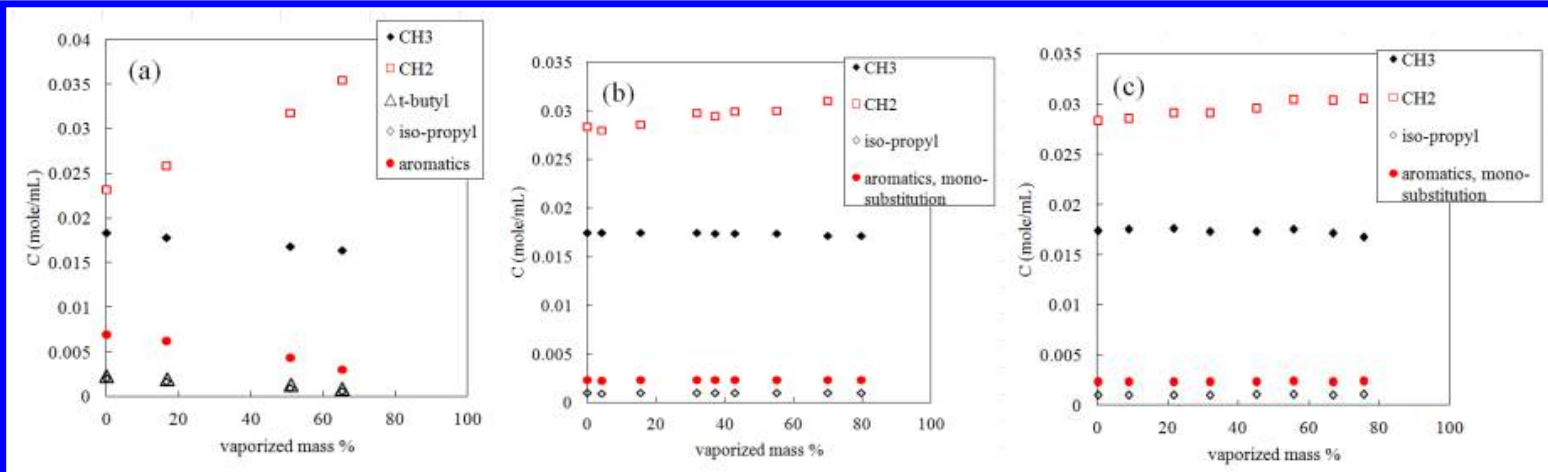

Figure 10. Evolution of functional group concentration in the liquid phase (a) surrogate evaporation; (b) Jet-A evaporation; (c) Jet-A burning.

that of Jet-A. In Fig. 10a, the clear increase of $\mathrm{CH}_{2}$ and decrease of $\mathrm{CH}_{3}$ indicate that the n-decane concentration is increasing with time. The concentration of t-butyl and iso-propyl are identical because iso-octane is the only compound in the surrogate mixture that provides these functional groups. In other words, these functional group concentrations can be used to represent the concentration of iso-octane in the liquid phase. Similarly, the aromatic concentration must equal to toluene concentration in the surrogate mixture. Figures 10b (Jet-A evaporation) and 10c (Jet-A burning) are almost identical. The functional group concentrations of Jet-A almost remain constant except for slight increase of $\mathrm{CH}_{2}$. The increase of $\mathrm{CH}_{2}$ may suggest the hydrocarbons with longer chains possessing higher volatilities tend to remain in the liquid fuel during evaporation or combustion processes.

Note that in both Figs. $10 \mathrm{~b}$ and $10 \mathrm{c}$ the legend of aromatics is followed by "mono-substitution." The reason being that a calibration curve of $727 \mathrm{~cm}^{-1}$ (Fig. 4d) was merely derived from toluene concentrations. Toluene has a mono-substituted methyl group on its benzene ring and the absorbance near $727 \mathrm{~cm}^{-1}$ as a result of the C-H out-ofplane bending in this molecular configuration. In fact, Jet-A has a much more complex pool of aromatic functional groups so the concentration of which must be obtained by benchmarking different aromatics. Regardless of the functional groups being attached on a benzene ring, different number of substitutions give very distinct peaks.

Figure 11 shows the comparison of FT-IR peaks of the various aromatics tested. It is evident that the Jet-A's aromatic peaks match the peaks from toluene, o-xylene, m-xylene, i.e. mono-, ortho-, and meta- substitutions, respectively. In the future, we attempt to complete the aromatic quantification by comparing the peaks with aromatics with two and three functional group substitution on a benzene ring. Also, attempts will be made to derive the evaporation parameters (e.g., activity coefficients) for surrogate components to match Jet-A's evaporation.

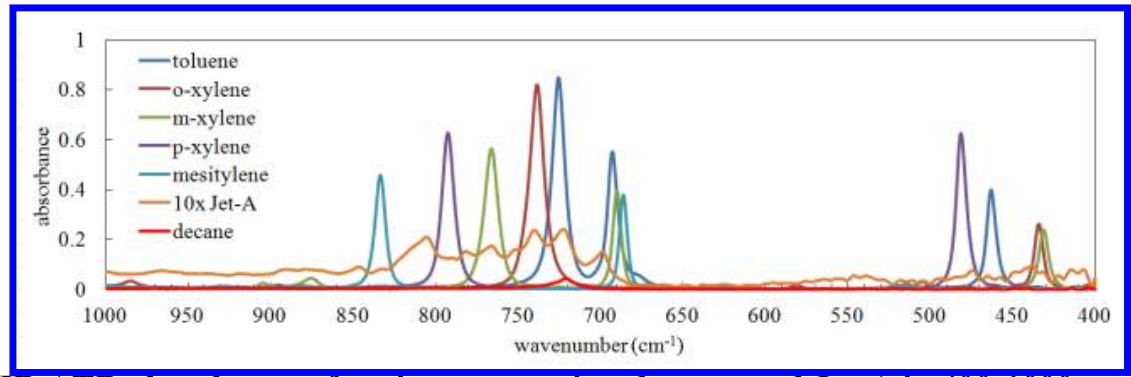

Figure 11. FT-IR ATR absorbance of various aromatics, decane, and Jet-A in $400-1000 \mathrm{~cm}^{-1}($ the aromatic region).

\section{Conclusion}

Hot plate evaporation experiments of small liquid amounts $(10 \mathrm{~mL})$ of Jet-A and its surrogate were carried out. The total evaporation time of the surrogate was much shorter than that of Jet-A because Jet-A consists of much heavier hydrocarbons that are less volatile. Correlations of FT-IR ATR absorbance and the corresponding concentration have been developed for $\mathrm{CH}_{2}\left(2853 \mathrm{~cm}^{-1}\right), \mathrm{CH}_{3}\left(2954 \mathrm{~cm}^{-1}\right)$, t-butyl $\left(1393 \mathrm{~cm}^{-1}\right)$, iso-propyl $\left(1365 \mathrm{~cm}^{-}\right.$ ${ }^{1}$ ), and mono-substituted aromatics (693 and $727 \mathrm{~cm}^{-1}$ ) using mixtures of n-decane, iso-octane, and toluene. These correlations are used to reveal the functional group concentrations in liquid from both evaporation and pool fire experiments. The evaporation functional group evolution of the surrogate was very different than that of Jet-A while the results from Jet-A evaporation seem almost identical as from Jet-A burning. Results show that $\mathrm{CH}_{2}$ concetration 
increases with time for evaporation of surrogate meaning n-decane is the less volatile component in the surrogate. $\mathrm{CH}_{2}$ concentration was also found to slightly increase for both Jet-A evaporation and burning. More work needs to be done to match various substitution modes on a benzene ring in order to better represent Jet-A's aromatics.

\section{Acknowledgments}

This study is financially supported by the Research and Creative Activity Fund (grant number- U046533) and the Start-Up Research Fund of University of Michigan - Flint. The authors thanks Dr. Terry Van Allen of the Office of research in UM-Flint for monitoring the grant, Dr. Nicholas Kingsley and Miss Monique Wilhelm of Department of Chemistry of UM-Flint for initial sample measurements using their FT-IR, and Tim Edwards of the WrightPatterson Air Force Base for providing the Jet-A used in this study. Assitance from Mr. Xiaoyi Ma of UM-Flint (now Lotus Engineering) with participating the beginning phase of this project is appreciated.

\section{References}

${ }^{1}$ Transforming combustion research through cyberinfrastructure. Committee on Building Cyberinfrastructure for Combustion Research, National Research Council, The National Academies Press, ISBN-13: 978-0-309-16387-3, April, 2011. $<$ http://www.nap.edu/catalog.php?record_id=13049>.

²Edwards, T.F. "Liquid fuels and propellants for aerospace propulsion: 1903-2003," AIAA J Propul Power Vol. 19, No. 6, 1986, pp. 1089-1107.

${ }^{3}$ Rahmes, T.F., Kinder, J.D., Henry, T.M., Crenfeldt, G., LeDuc, G.F., Zombanakis, G.P., Abe, Y., Lambert, D.M., Lewis, C., Juenger, J.A., Andac, M.G., Reilly, K.R., Holmgren, J.R., McCall, M.J., Bozzano, A.G., "Sustainable Bio-Derived Synthetic Paraffinic Kerosene (Bio-SPK) Jet Fuel Flights and Engine Tests Program Results," $9^{\text {th }}$ AIAA Aviation Technology, Integration, and Operations Conference (ATIO) Sep. 21-23, 2009, South California, AIAA 2009-7002.

${ }^{4}$ Blakey, S., Rye, L., Wilson, C.W., “Aviation gas turbine alternative fuels: A review,” Proc. Combust. Inst. Vol. 33, 2011, pp.2863-2855.

${ }^{5}$ Liu, Y.C., Savas, A.J., Avedisian, C.T., "The spherically symmetric droplet burning characteristics of Jet-A and biofuels derived from camelina and tallow," Fuel Vol. 108, 2013, pp. 824-832.

${ }^{6}$ Viljoen, C.L., Van Zyl, V.L., Van Tender, E.H., "Synthetic aviation fuel," US Patent, 2013, US 8597493 B2.

$\checkmark{ }^{7}$ Humer, S., Seiser, R., Seshadri, K., "Experimental investigation of combustion of jet fuels and surrogates in nonpremixed flows," J. Propul. Power Vol. 27, No. 4, 2011, pp. 847-855.

${ }^{8}$ Holley, A.T., Dong, Y., Andac, M.G., Egolfopoulos, F.N., Edwards, T., "Ignition and extinction of non-premixed flames of single-component liquid hydrocarbons, jet fuels, and their surrogates," Proc. Combust. Inst. Vol. 31, 2007, pp. $1205-1213$.

${ }^{9}$ Colket, M., Edwards, T., Williams, S., Cernansky, N.P., Miller, D.L., Egolfopoulos, F., Lindstedt, P., Seshadri, K., Dryer, F.L., Law, C.K., Friend, D., Lenhert, D.B., Pitsch, H., Sarofim, A., Smooke, M., Tsang, W., "Development of an experimental database and kinetics models for surrogate jet fuels," $45^{\text {th }}$ AIAA Aerospace Sciences Meeting and Exhibit, Reno, NV, Jan. 8-11, AIAA 2007-0770.

${ }^{10}$ Bruno, T.J., Huber, M.L., "Evaluation of the physicochemical authenticity of aviation kerosene surrogate mixtures. Part 2: analysis and prediction of thermophysical properties," Energy Fuels Vol. 24, 2010, pp. 4277-4284.

11 Jahangirian, S., McEnally, C.S., Gomez, A., "Experimental study of ethylene counterflow diffusion flames perturbed by trace amounts of jet fuel and jet fuel surrogates under incipiently sooting conditions," Combust. Flame Vol. 156, 2009, pp. 17991809.

${ }^{12}$ Dooley, S., Won, S.H., Chaos, M., Heyne, J., Ju, Y., Dryer, F.L., Kumar, K., Sung, C.-J., Wang, H., Oehlschlaeger, M.A., Santoro, R.J., Litzinger, T.A., “A jet fuel surrogate formulated by real fuel properties,” Combust. Flame Vol. 157, 2010, pp. 2333-2339.

${ }^{13}$ Dooley, S., Won, S.H., Chaos, M., Heyne, J., Farouk, T.I., Ju, Y., Dryer, F.L., Kumar, K., Hui, X., Sung, C.-J., Wang, H., Oehlschlaeger, M.A., Iyer, V., Iyer, S., Litzinger, T.A., Santoro, R.J., Malewicji, T., Brezinsky, K., "The experimental evaluation of a methodology for surrogate fuel formulation to emulate gas phase combustion kinetic phenomena," Combust. Flame Vol. 159, 2012, pp. 1444-1466.

${ }^{14}$ Dussan, K., Dooley, S., Dryer, F.L., Won, S.H., "A nuclear magnetic resonance oriented combustion property regression," $9^{\text {th }}$ U.S. National Combustion Meeting, May 17-20, 2015, Cincinnati, Ohio, paper \# 3C06.

$\checkmark{ }^{15}$ Burger, J.L., Bruno, T.J., "Applicatoin of the adcanced distillation curve method to the variability of jet fuels," Energy Fuels Vol. 26, 2012, 3661-3671.

${ }^{16}$ Smith, B.L., Bruno, T.J., "Improvements in the measurement of distillation curves. 4. Application to the aviation turbine fuel Jet-A,” Ind. Eng. Chem. Res., Vol. 46, 2007, pp. 310-320.

$\checkmark{ }^{17}$ Kock, E.-M, Kogler, M., Pramsoler, R., Klotzer, B., Penner, S., “A high-temperature, ambient-pressure ultra-dry operand reactor cell for Fourier-transform infrared spectroscopy,” Rev. Sci. Instrum., Vol. 85, 2014, pp. 084102.

${ }^{18} \mathrm{Li}$, J., Kazakov, A., Dryer, F.L., "Ethanol pyrolysis experiments in a variable pressure flow reactor," Int. J. Chem. Kinetics Vol. 33, 2011, pp. 859-867.

${ }^{19}$ Klingbeil, A.E., Jefferies, J.B., Hanson, R.K., “ Temperature- and pressure-dependent absorption cross sections of gaseous hydrocarbons at 3.39 um,” Meas. Sci. Technol. Vol. 17, 2006, pp. 1950-1957. 
${ }^{20}$ Spearrin, R.M., Li, S., Davidson, D.F., Jeffries, J.B., Hanson, R.K., "Higher-temperature iso-butene absorption diagnostic for shock tube kinetics using a pulsed quantum cascade laser near $11.3 \mu \mathrm{m}$," Proc. Combust. Inst. Vol. 35, 2015, pp. 3645-3651.

${ }^{21}$ Liu, Y.C., Savas, A.J., Avedisian, C.T., "Spherically symmetric droplet combustion of three and four component miscible mixtures as surrogates for Jet-A," Proc. Combust. Inst. Vol. 34, 2013, pp. 1569-1576.

$\checkmark 22$ Klingbeil, A.E., Jeffries, J.B., Hanson, R.K., "Temperature-dependent mid-IR absorption spectra of gaseous hydrocarbons," J. Quantitative Spectroscopy \& Radiative Transfer Vol. 107, 2007, pp. 407-420.

${ }^{23}$ Silverstein, R.M., Webster, F.X., Kiemle, D.J., Spectrometric Identification of Organic Compounds, $7^{\text {th }}$ edition, John Wiley \& Sons, Inc., 2005, Chap 2. 
This article has been cited by:

1. Ke-Feng Song, Guang-Fu Ji, Kotni Meena Kumari, Dong-Qing Wei. 2018. Blending effect between $n$-decane and toluene in oxidation: a ReaxFF study. Molecular Simulation 44:1, 21-33. [Crossref] 